\title{
Study on microheterogeneity and seepage law of reservoir after long-term water flooding
}

\author{
Hua Wen ${ }^{1}$ (D) Yikun Liu $^{1} \cdot$ Na Sun $^{2}$
}

Received: 4 July 2016/Accepted: 12 March 2017/Published online: 22 March 2017

(C) The Author(s) 2017. This article is an open access publication

\begin{abstract}
In order to carry out research on variation of microheterogeneity in sandstone reservoir after long-term water flooding in the complex faulted oilfields, the cores are cut from typical wells of main oil layers of two blocks in the Jidong Oilfield, and the experiments of long-term water flooding are conducted. Based on the mercury-injection data at different water cut stages during water flooding and the digital core data reconstructed by X-ray CT scanning, the variation of microheterogeneity of reservoir at different water cut stages during long-term water flooding of core are quantitatively characterized through fractal dimension method and 3D pore network model, and the rule of oil-water seepage at different water cut stages is characterized. The study showed that the middle-high-permeability reservoir has a good fractal structure with fractal dimension between 2 and 3 . The large pore has the less fractal dimension, and the better homogeneity and pore structure than the small one. After the cores are washed by long-term water flooding, and as the water cut increases, the fractal dimensions of large and small pore gradually decrease, mean and medium pore diameters increase, the relative sorting coefficient decreases, the distribution probability of throat radius of core generally increases, and the microheterogeneity of reservoir weakens. Moreover, the oil relative permeability curves are almost overlapped, and the water relative permeability curves result in a big difference. Under the same
\end{abstract}

Hua Wen

wenhuazhg@126.com

1 College of Petroleum Engineering, Northeast Petroleum University, Daqing 163318, Heilongjiang, China

2 Songyuan Gas Recovery Plant, Petro China Jilin Oilfield Company, Songyuan 138000, China water saturation, as the water cut increases, the fractal dimension decreases, the water relative permeability increases, and the oil-water common seepage points shift to the left.

Keywords Microheterogeneity $\cdot$ Mercury injection $\cdot$ X-ray CT scanning $\cdot$ Digital core $\cdot$ Fractal $\cdot 3 \mathrm{D}$ pore network model $\cdot$ Relative permeability curves

\section{Introduction}

The microheterogeneity of reservoir is one of the key factors affecting the remaining oil and the ultimate oil recovery. Accurate quantitative characterization of microheterogeneity of reservoir pore structure is always challenging (Hewett 1986; Ross and Kovscek 2002; Yang et al. 2014), especially in the reservoir under long-term water flooding where the micropore structure has changed. Thus, it is important to carry out quantitative research on variation of microheterogeneity of reservoir, which plays a significant role in guiding adjustment of development plan, quantitative characterization of remaining oil, tertiary oil recovery, and enhanced ultimate oil recovery ( $\mathrm{Li}$ et al. 2002, 2007; Shi et al. 2013).

The complex and irregular micropore structure of reservoir results in the complicated nonlinear problem of microheterogeneity. The macropore parameters given by traditional Euclidean theory, rock cast slice, scanning electron microscopy (SEM), and logging only reflect overall pore characteristics of core, and could not accurately quantify microheterogeneity of reservoir (Han et al. 2006; Sondergeld et al. 2010). By combining mathematics with computer science, the researchers improved the methods of characterizing pore structure, which evolved 
from qualitative characterization to semi-quantitative and quantitative characterization. Shen et al. (1995), Libny et al. (2001), Bijan (2003), and Sigal (2013) tested the capillary pressure curves through mercury injection to obtain the parameters reflecting throat size, connectivity, and permeability. The mercury injection provides the semiquantitative study on the pore structure in a quick and accurate manner, but could not quantitatively characterize the micropore structure. Mandelbrot (1982), a French mathematician, put forward the fractal geometry, which revolutionized the classical geometry, and the theory provides a new method to characterize and study the micropore structure. Katz and Thompson (1985) firstly applied the fractal geometry theory in analysis of the structure of porous media, which showed that both pore space and interface in porous media have fractal structure. Angulo et al. (1992), Becker et al. (1997), Perez and Chopra (1997), Shen et al. (1998), He and Hua (1998), Radlinski et al. (1999), Perez and Miguel 2001, Li (2004), Li and Horne (2006), and Ma et al. (2005), put forward various mathematical models of computing the fractal dimension of pore structure based on mercury-injection data with fractal theory and achieved a significant fruit.

However, in terms of dynamic change (Lin et al. 2001, 2008; Cai et al. 2004), few scholars have applied fractal theory to quantitatively characterize variation of heterogeneity of pore structure in long-term water flooding reservoir (Wang et al. 2005). Thus, it is necessary to carry out research to promote development of fractal theory applied in analysis of pore structure. The pore space is a complex 3D network composed of connected throat and pore space. Since the pore network model was proposed by Fatt $(1956 a$, b, c) in 1956, it has been a powerful tool to study microscopic reservoir structure and seepage characteristics. Elliott and Dover (1982), Sorbie et al. (1989), Lymberopoulos and Payatakes (1992), Xu et al. (1999), Fredrich et al. (1995), Fredrich (1999), Delerue et al. (1999), Lindquist and Venkatarangan (1999), Liang et al. (2000), Blunt (2001), Radlinski et al. (2002), Siddiqui and Khamees (2004), Coenen et al. (2004), Knackstedt et al. (2006), Al-Kharusi and Blunt (2007), Tomutsa et al. (2007), Dong and Blunt (2009), Peng et al. (2012), Saurabh et al. (2013), Theis et al. (2014), have researched the technologies and algorithms of constructing the digital core and 3D pore network model, and the 3D pore network model has been rapidly developed and widely applied. Among those technologies, the method of constructing 3D pore network model with digital core reconstructed by high-precision X-ray CT scanning is dominant, and it is future direction of researching microstructure of reservoir pore (Hou et al. 2007; Arns et al. 2004, 2005; Youssef et al. 2008; Mustafa et al. 2009). However, limited by equipment and technological conditions, China has not achieved much fruits in the field of reconstructing 3D pore network model. The technology of reconstructing 3D pore network model is rarely applied in microscopic evaluation of reservoir, and there are few reports about its application in evaluating variation of microheterogeneity of reservoir under long-term water flooding ( $\mathrm{Xu}$ et al. 2010).

Obviously, the fractal geometry theory and 3D pore network model play a significant role in quantitative characterization of microheterogeneity of reservoir. However, there is little study on its application in evaluating microstructure of reservoir pore under long-term water flooding. Therefore, the cores are cut from typical wells of major oil layers of two blocks in the Jidong Oilfield, and the experiments of long-term water flooding are conducted. Moreover, with fractal theory and 3D model of pore network, the variation of microheterogeneity of reservoir at different water cut stages during long-term water flooding was studied based on the high-precision mercury-injection data and the digital core data reconstructed by X-ray CT scanning. The micropore structure is characterized to obtain characteristic parameters describing its complexity and irregularity, and the rules of oil-water seepage at different water cut stages are described through fractal method.

\section{Core experiment of long-term water flooding}

\section{Experimental conditions}

Experimental temperatures: the room temperature is $20^{\circ} \mathrm{C}$, and the simulated reservoir temperature is $85^{\circ} \mathrm{C}$. Oil tested in experiment: oil is sampled from two types of reservoirs in the Jidong oilfield (Fig. 1). At $85^{\circ} \mathrm{C}$, the oil viscosity of Well LN103 and LN2-6 in light oil reservoir is $3.6 \mathrm{mPa} \mathrm{s}$, and that of Well G206-4 and GJ315-7 in heavy oil reservoir is $90 \mathrm{mPa}$ s. Water tested in experiment: Rhe injection water is prepared according to the mineralization of $1974.1 \mathrm{mg} / \mathrm{L}$ from formation water analysis of $\mathrm{Nm}$ III and $\mathrm{Ng}$ of the Jidong oilfield. At $85^{\circ} \mathrm{C}$, the water viscosity is $0.68 \mathrm{mPa}$ s. Core tested in experiment: Cylindrical natural core is cut from Well LN103, LN2-6, G206-4 and GJ315-7 of Nm III of LN and GJ Blocks of the Jidong oilfield, and each core is divided equally into four pieces. The core parameters are listed in Table 1.

The representative depth, porosity, and permeability of core samples are chosen in the experiment of long-term water flooding, and the process that core is saturated with oil could characterize real reservoir condition. The irreducible water is created, and the core is aged. The flow rate during saturating oil and water flooding are controlled based on the sensitivity. 


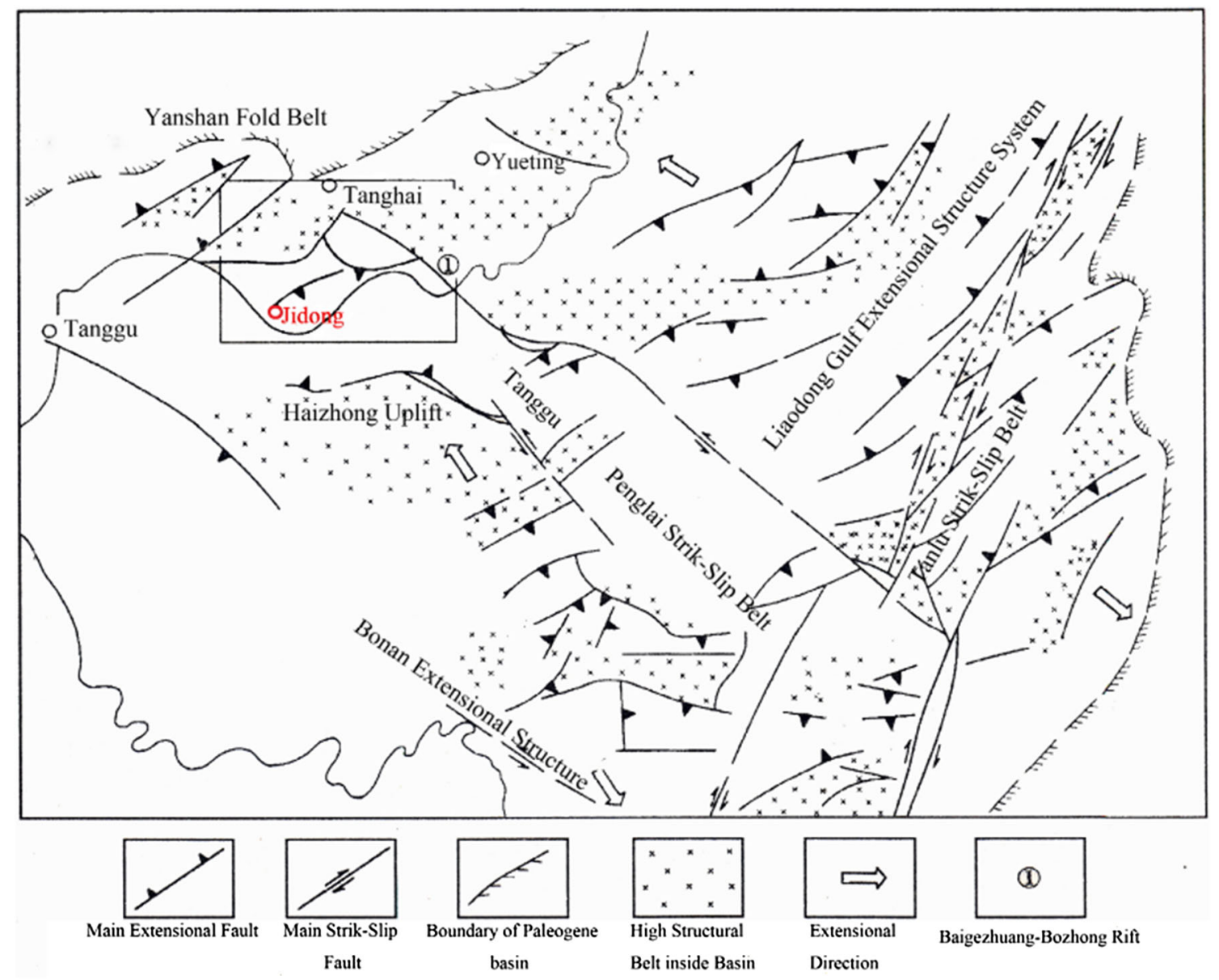

Fig. 1 Tectonic location of the Jidong oilfield

Table 1 Core data in experiment

\begin{tabular}{|c|c|c|c|c|c|c|c|c|c|}
\hline Block & Type & Well & Oil layer & Core no. & Length/mm & Diameter/mm & $\begin{array}{l}\text { Permeability measured } \\
\text { with gas } / 10^{-3} \mu \mathrm{m}^{2}\end{array}$ & Porosity/\% & $\begin{array}{l}\text { Shale } \\
\text { content } / \%\end{array}$ \\
\hline LN & Thin oil & LN103 & Nm III & L1 & 240 & 48 & 1740 & 30.56 & 3.4 \\
\hline LN & Thin oil & LN2-6 & Nm III & L2 & 240 & 48 & 1540 & 30.12 & 3.6 \\
\hline GJ & Heavy oil & G206-4 & $\mathrm{Ng}$ & G1 & 240 & 48 & 1810 & 31.47 & 4.2 \\
\hline GJ & Heavy oil & GJ315-7 & $\mathrm{Ng}$ & G2 & 240 & 48 & 1909 & 31.32 & 3.7 \\
\hline
\end{tabular}

\section{Experimental method}

The procedure of physical simulation of long-term water flooding is shown in Fig. 2 (the solid line represents the process before water flooding, and the dotted line represents the process after water flooding). At first, the rock samples are washed and dried to measure air permeability, and the samples are saturated with water to measure the porosity. The capillary pressure data are measured through mercury injection, and the relative permeability curve data are measured through displacing oil with water.
Meanwhile, the cores are cut to make thin slices. Then, the physical simulation experiment of long-term water injection is conducted. The water flooding is conducted in natural cores, and the water flooding velocity is controlled within critical velocity. The water flooding continues until the water cut reaches 60,80 , and $90 \%$, respectively. Then, the core samples are dried again to measure permeability, porosity, mercury-injection capillary pressure, and the relative permeability curve. The cores are cut to make thin slices again. At different stages of water cut, the mercury injection and the construction of digital core based on 


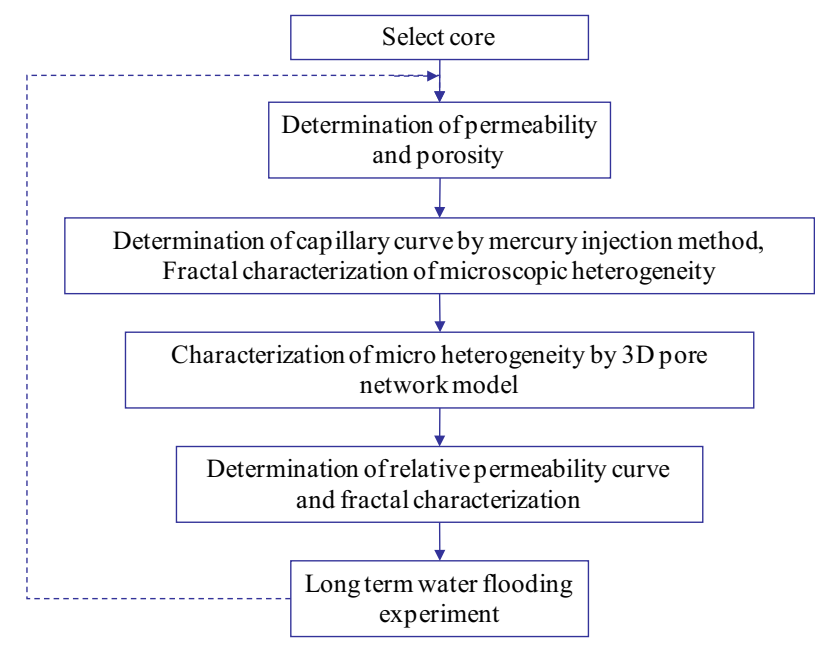

Fig. 2 Procedure of long-term water flooding experiment

$\mathrm{X}$-ray-CT scanning provide basic data for characterizing the influence of long-term water flooding on microheterogeneity of reservoir and its variation.

\section{Procedure of experiment}

1. Cut natural cores from main oil layers of typical wells of two types of oil reservoir in the Jidong Oilfield, and clean the cores to remove the initial oil.

2. Test porosity, permeability, and capillary pressure curve of core.

3. Test relative permeability curve through transient method.

4. Weigh the dried rock sample. Evacuate the air in the sample and saturate it with formation water. Then, weigh the sample again to calculate pore volume.

5. Put the sample saturated with formation water in the core holder.

6. Displace the water with simulation oil in cores to create the irreducible water saturation. At the end of displacement, record the volume of displaced water.

7. Displace oil with water at a constant speed until the water cut reaches 60,80 , and $90 \%$, respectively.

8. Displace oil with water to different water cut. At the end of experiment, remove the fluid in core and dry the core. Then, cut core columns. Conduct mercuryinjection analysis and relative permeability curve analysis in four pieces of cores under water flooding and other four pieces of cores without water flooding. Conduct fractal analysis of microheterogeneity with mercury- injection data, and cut the core to make thin slices. Reconstruct the digital cores with CT scanning method, and construct 3D pore network model to analyze the micropore structure. Compare and analyze the data of different water cut.

\section{Fractal characterization of microheterogeneity of reservoir}

\section{Fractal model of microheterogeneity}

The micropore structure of reservoir shows the fractal characteristics, and the complexity of microstructure of reservoir pore is characterized with fractal characteristics of mercury-injection capillary pressure curve. Thus, the fractal of capillary pressure curve is expressed by Shen et al. (1998):

$S_{w}=\left(\frac{p_{\min }}{p_{c}}\right)^{3-D}$

where $S_{w}$ is the saturation of wetting phase of mercuryinjection capillary pressure curve under reservoir condition, decimal; $p_{\min }$ is the capillary pressure corresponding to maximum throat radius in mercury-injection capillary pressure curve under reservoir condition, which is entry capillary pressure or threshold pressure, $\mathrm{MPa} ; p_{c}$ is capillary pressure, $\mathrm{MPa} ; D$ is the fractal dimension of micropore structure, decimal.

Through logarithmic transformation on both ends of Formula (1), it can be obtained that:

$\lg S_{w}=(-D+3) \lg p_{\min }+(D-3) \lg p_{c}$

which shows that there is a linear relationship between $S_{w}$ and $p_{c}$ in $\log -\log$ coordinate. Thus, the linear regressive analysis of Formula (2) is operated with mercury-injection data, the fractal dimension $D$ is calculated with the slope of straight line, and the threshold pressure $p_{\min }$ is calculated with the intercept.

Fractal model Formulas (3)-(5) are function of variation coefficient, skewness and characteristic value of pore structure. The relation between the characteristic parameters of pore structure and its fractal dimension is obtained by substituting fractal dimension $D$ into Formulas (3)-(5). These characteristic parameters of pore structure are parameters characterizing its microheterogeneity.

Variation coefficient of pore structure $(C)$ : it is a physical quantity characterizing relative distribution uniformity of pore size. The smaller variation coefficient corresponds to the more uniform pore distribution. The fractal model is expressed by Perez and Miguel (2001):

$C=\sqrt{\frac{(4-D)^{2}}{(3-D)(5-D)}-1}$

Skewness $\left(S_{h}\right)$ : it is a physical quantity characterizing distribution of pore size, and it defines pore distribution toward large pore or small one when compared with average value. Its fractal model is expressed by $\mathrm{He}$ and Hua (1998): 
$S_{h}=\frac{\frac{3-D}{6-D}-\frac{3(3-D)^{2}}{(4-D)(5-D)}+2\left(\frac{3-D}{4-D}\right)^{3}}{\left[\frac{3-D}{5-D}-\left(\frac{3-D}{4-D}\right)^{2}\right]^{\frac{3}{2}}}$

Function of characteristic value of pore structure $(G(f))$ : it is a characteristic value considering pore separation, skewness, and average radius, and it is product of variation coefficient of pore structure and skewness. The parameter quantitatively characterizes the comprehensive characteristics of micropore structure, and the fractal model is expressed by Ma et al. (2005), Li and Horne (2006):

$$
\begin{aligned}
G(f) & =C \cdot S_{h} \\
& =\frac{\frac{3-D}{6-D}-\frac{3(3-D)^{2}}{(4-D)(5-D)}+2\left(\frac{3-D}{4-D}\right)^{3}}{\left[\frac{3-D}{5-D}-\left(\frac{3-D}{4-D}\right)^{2}\right]^{\frac{3}{2}}} \cdot \sqrt{\frac{(4-D)^{2}}{(3-D)(5-D)}-1}
\end{aligned}
$$

\section{Fractal study on variation of microheterogeneity at different water cut}

Cores are cut from Well LN103 in light oil reservoir and Well GJ315-7 in heavy oil reservoir in the Jidong Oilfield. All cores have high porosity and permeability, and the pore structure is representative in light and heavy oil reservoir. In order to study the influence of long-term water flooding on micropore structure, each type of core is divided to 4 pieces (Table 2). L1-1 core is not water flooded, and L1-2, L1-3, and L1-4 cores are water flooded to water cut of 60,80 , and $90 \%$, respectively. Then, mercury-injection experiments are conducted with cores after and without water flooding to obtain 8 sets of capillary pressure data.

Generally, a small amount of mercury is adsorbed on the surface of rock because of rough rock surface before pressurizing in mercury-injection experiment. Thus, the initial segment of capillary pressure curve does not reflect the characteristics of pore structure. In order to eliminate its influence, the data of initial segment of mercury-injection curve are ignored during calculating fractal dimension,

Table 2 No. of core in mercury-injection experiment

\begin{tabular}{lll}
\hline $\begin{array}{l}\text { Different stages during } \\
\text { water flooding }\end{array}$ & $\begin{array}{l}\text { No. of core in } \\
\text { Well LN103 }\end{array}$ & $\begin{array}{l}\text { No. of core in } \\
\text { Well GJ315-7 }\end{array}$ \\
\hline $\begin{array}{lll}\text { Non-water flooding } \\
\text { Water cut of } 60 \%\end{array}$ & L1-1 & G2-1 \\
Water cut of $80 \%$ & L1-3 & G2-2 \\
Water cut of $90 \%$ & L1-4 & G2-3 \\
\hline
\end{tabular}

and only the data with mercury saturation over $5 \%$ are used.

Fractal study on micropore structure of Well LN103 in light oil reservoir

Based on mercury-injection capillary pressure data at four stages of water cut, the regression of relation between $S_{w}$ and $p_{c}$ (Fig. 3a-d) is operated with Formula (2), and all regression at four stages of water cut has a high precision. The fractal dimensions of pore structure at four stages of water cut calculated based on regression are shown in Table 3, which shows that all fractal dimensions are between 2 and 3, and have a good correlation. It is indicated that all core samples have fractal structure. The fractal dimension closer to 2 corresponds the more uniform pore structure. The fractal dimension closer to 3 corresponds to the less uniform pore structure. For core samples with same high porosity and permeability, the fractal dimension of pore structure gradually decreases as the water cut increases, and the variable coefficient, the skewness, and the function of characteristic value decrease after long-term water flooding. It is showed that the microheterogeneity of pore structure decreases, namely that the pore structure is more uniform as the water cut increases. The main reason is that after long-term water flooding and washing, the microparticle in reservoir and decomposed clay mineral fragment are scattered and migrated, and evenly discharged with produced fluid, which makes throat more open. The supporting mode of frame particle is changed from dot-line contact to fluid mounting, and the connectivity of pore-throat network becomes better. The pore becomes less disperse, and the separation gets better as the data points move closer to the center of mean value. The rule has not been reported before (Angulo et al. 1992; Shen et al. 1995, 1998; Becker et al. 1997; Perez and Chopra 1997; He and Hua 1998; Radlinski et al. 1999; Perez and Miguel 2001; Libny et al. 2001; Bijan 2003; Li 2004; Ma et al. 2005; Han et al. 2006; Li and Horne 2006; Sondergeld et al. 2010; Sigal 2013).

Meanwhile, the relation curve of $D$ and water cut $f_{w}$ is drawn in the rectangular coordination system with water cut $f_{w}$ as $x$-axis and fractal dimension $D$ as $y$-axis, and regression of data is conducted to obtain relation between fractal dimension and water cut exponent: $D=2.6973 \exp \left(-0.0557 f_{w}\right)$, with correlation coefficient $R^{2}=0.9966$. Based on the matched equation, the variation of fractal dimension $D$ of micropore structure at different stages of water cut is predicted, which has not been reported (Lin et al. 2001; Cai et al. 2004; Wang et al. 2005; Lin et al. 2008). Thus, the influence of longterm water flooding on micropore structure of core is 

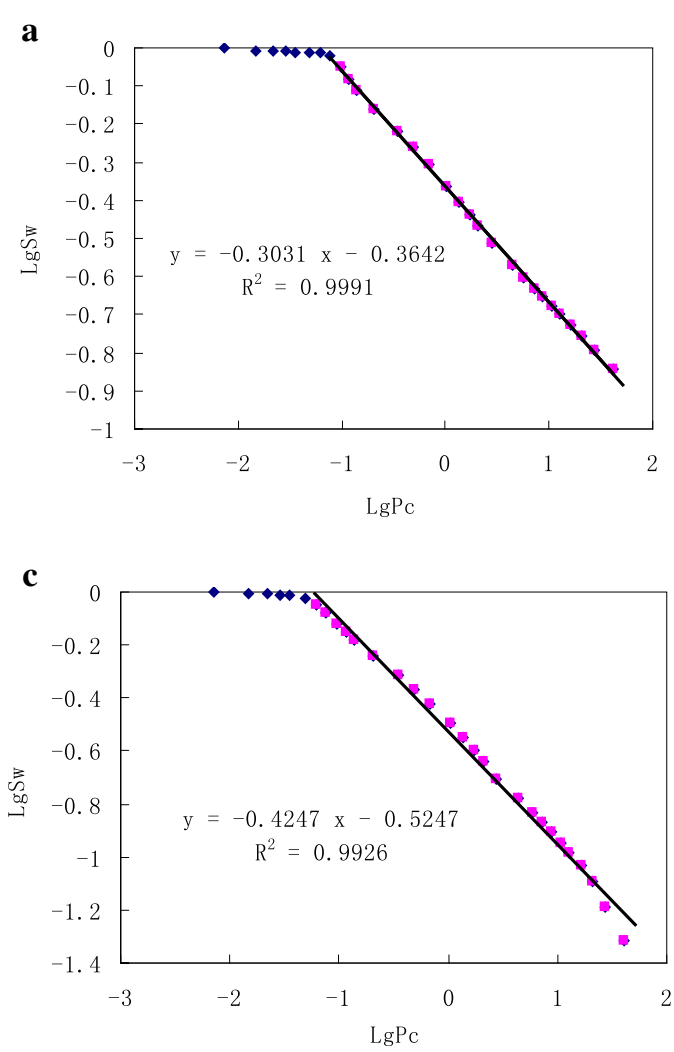

Fig. 3 a Fitting $\log -\log$ graph of capillary pressure and saturation of core without water flooding from Well LN103. b Fitting $\log -\log$ graph of capillary pressure and saturation of core with water cut of $60 \%$ from Well LN103. c Fitting log-log graph of capillary pressure $\mathbf{b}$

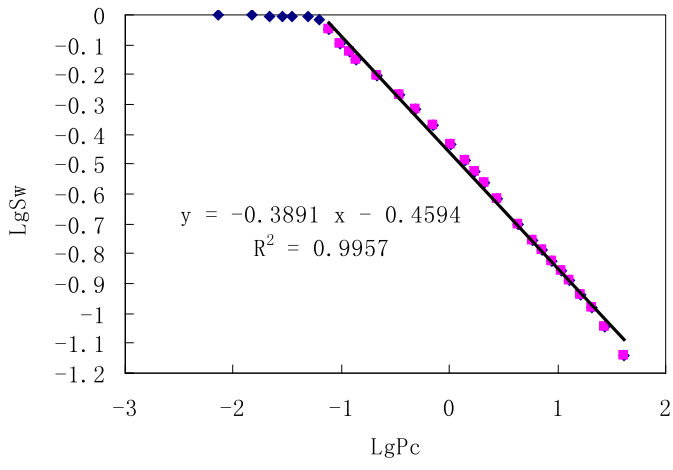

d

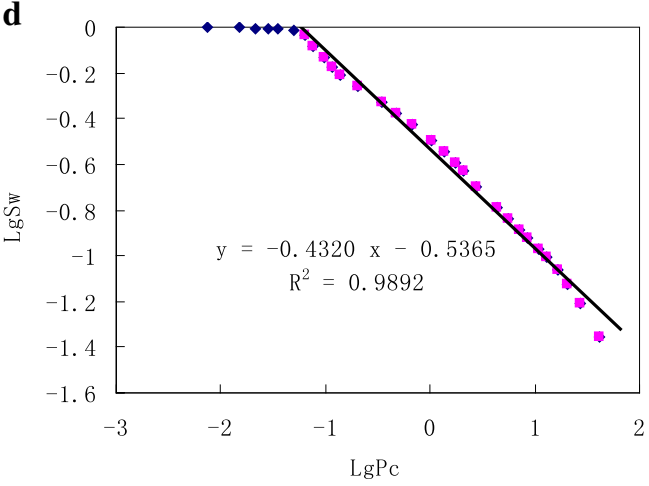

and saturation of core with water cut of $80 \%$ from Well LN103. d Fitting $\log -\log$ graph of capillary pressure and saturation of core with water cut of $90 \%$ from Well LN103

Table 3 Fractal dimensions of micropore structure at different stages of water cut of core from Well LN103

\begin{tabular}{llllll}
\hline $\begin{array}{l}\text { Different stages of } \\
\text { water flooding }\end{array}$ & $\begin{array}{l}\text { Fractal } \\
\text { dimension } D\end{array}$ & $\begin{array}{l}\text { Threshold pressure } \\
p_{\text {min }}(\mathrm{MPa})\end{array}$ & $\begin{array}{l}\text { Variable } \\
\text { coefficient } C\end{array}$ & Skewness $S_{h}$ & $\begin{array}{l}\text { Function of characteristic } \\
\text { value } G(f)\end{array}$ \\
\hline Initial stage & 2.697 & 0.063 & 1.197 & 1.1632 & 1.3922 \\
Water cut of $60 \%$ & 2.611 & 0.066 & 1.037 & 0.8933 & 0.9265 \\
Water cut of $80 \%$ & 2.575 & 0.057 & 0.985 & 0.8028 & 0.7911 \\
Water cut of $90 \%$ & 2.568 & 0.055 & 0.976 & 0.7854 & 0.7662 \\
\hline
\end{tabular}

quantified based on fractal principle to provide theoretical basis for studying micropore structure of core at different stages of water cut.

\section{Fractal study on micropore structure of Well GJ315-7 in heavy oil reservoir}

The complex primary deposit in Gaoqianbei Block and transformation of later diagenesis in the Jidong Oilfield resulted in the complex pore structure in high-porosity and high-permeability reservoir. The pore of different characteristics is distributed unevenly in reservoir. There is no good linearity between the logarithm of capillary pressure and the logarithm of wetting phase, and the data show apparent segmentation. During regression fitting of capillary pressure data, there is a large difference between computation result and real result in case of overall regression of all data without treatment, and only regression of some data, and the computation result could not reflect real distribution of pore structure. Thus, during computing the fractal dimension of pore structure in the high-permeability and high-porosity reservoir, the separate fitting and regression of data should be conducted based on distribution of data and pore size, which not only ensures integrity of data, but also reflects pore distribution. Fig. 4a$\mathrm{d}$ shows that two straight sections appear in log-log graph of capillary pressure and saturation of cores of Well GJ315-7 in heavy oil reservoir at four stages of water cut. 
a

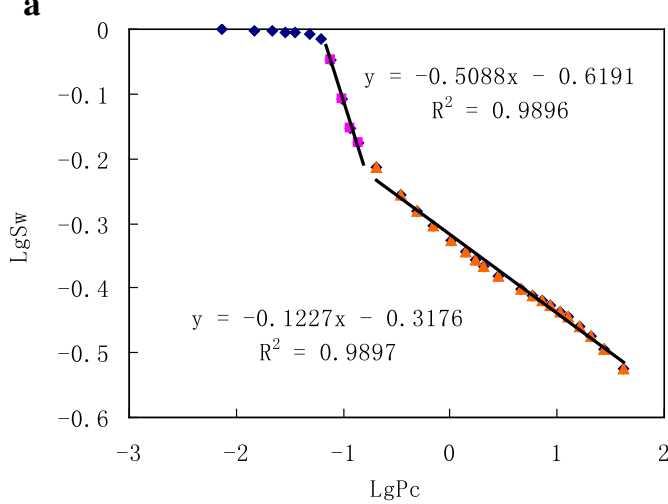

c

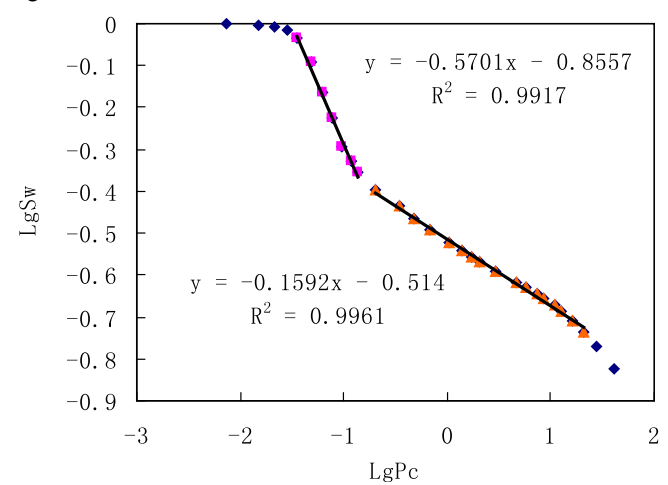

Fig. 4 a Fitting $\log -\log$ graph of capillary pressure and saturation of core without water flooding in Well GJ315-7. b Fitting log-log graph of capillary pressure and saturation of core with water cut of $60 \%$ in Well GJ315-7. c Fitting $\log -\log$ graph of capillary pressure and

The upper section represents fractal characteristics of structure of large pores, and the lower section represents those of small ones. The fractal dimensions of structure in Table 4 show that fractal dimensions of large and small pores are between 2 and 3, and both large and small pores have the fractal structure. Moreover, the fractal dimensions of large pores are less than those of small ones. Thus, in terms of heavy oil reservoir represented by Well GJ315-7, the structure of large pores is more uniform than that of small ones. After long-term water flooding in heavy oil reservoir, fractal dimensions of both large and small pores, variable coefficient, skewness, and characteristic function of pore structure decrease as the water cut increases. It indicates that the microheterogeneity of core decreases after long-term water flooding (Angulo et al. 1992; Shen et al. 1995, 1998; Becker et al. 1997; Perez and Chopra 1997; He and Hua 1998; Radlinski et al. 1999; Perez and Miguel 2001; Libny et al. 2001; Bijan 2003; Li 2004; Ma et al. 2005; Han et al. 2006; Li and Horne 2006; Sondergeld et al. 2010; Sigal 2013).

Likewise, the relation curve of fractal dimension of large and small pores $D$ and water cut $f_{w}$ is plotted in rectangular coordination system with water cut $f_{w}$ as $x$-axis

b

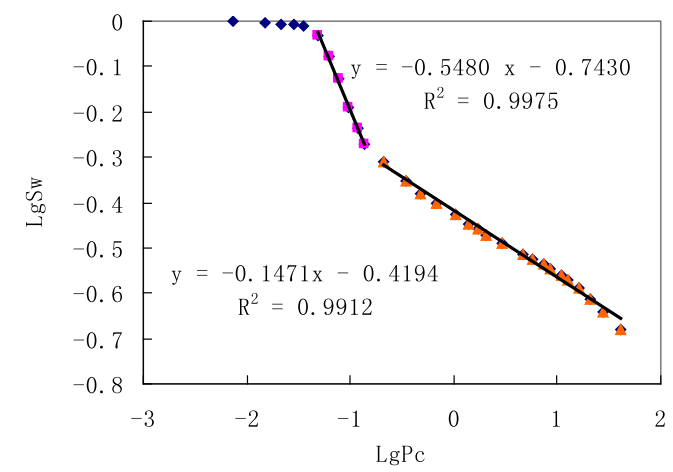

d

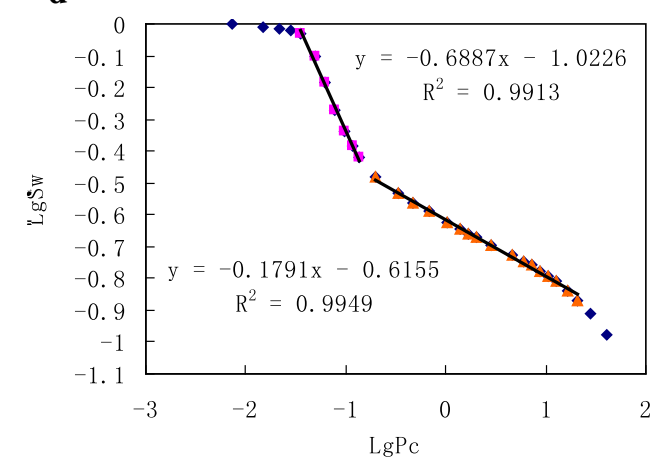

saturation of core with water cut of $80 \%$ in Well GJ315-7. d Fitting $\log -\log$ graph of capillary pressure and saturation of core with water cut of $90 \%$ in Well GJ315-7

and fractal dimension $D$ as $y$-axis, and the regression of data is conducted to obtain the regressive relation between fractal dimension and water cut exponent. For large pores: $D=-0.463 f_{w}^{2}+0.246 f_{w}+2.489$, correlation coefficient is $R^{2}=0.858$. For small pores: $D=-0.075 f_{w}^{2}+0.009 f_{w}+$ $2.876, R^{2}=0.975$. The variation rule of fractal dimension $D$ of microstructure of large and small pores at different stages of water cut is predicted based on the matched equation.

\section{Quantitative study on variation of microheterogeneity with 3D pore network model}

3D pore network model is an important tool to study micropore structure and macroscopic seepage characteristics of reservoir. The network model is composed of throats and connected pore bodies. The throat represents narrow and long pore space, and the pore body represents the larger pore space in connection of throat. The pore body and throat are defined as the ideal geometrical shapes with corresponding geometrical parameters, and the connectivity between pore is characterized with coordination 
Table 4 Fractal dimension of micropore structure at different water cut stages of core from Well GJ315-7

\begin{tabular}{|c|c|c|c|c|c|c|c|c|c|c|}
\hline \multirow{2}{*}{$\begin{array}{l}\text { Different Stages } \\
\text { of Water } \\
\text { Flooding }\end{array}$} & \multicolumn{2}{|c|}{ Fractal dimension $D$} & \multicolumn{2}{|c|}{$\begin{array}{l}\text { Threshold pressure } \\
p_{\min }(\mathrm{MPa})\end{array}$} & \multicolumn{2}{|c|}{$\begin{array}{l}\text { Variable coefficient } \\
C\end{array}$} & \multicolumn{2}{|c|}{ Skewness $S_{h}$} & \multicolumn{2}{|c|}{$\begin{array}{l}\text { Function of characteristic } \\
\text { value } G(f)\end{array}$} \\
\hline & $\begin{array}{l}\text { Large } \\
\text { pore }\end{array}$ & $\begin{array}{l}\text { Small } \\
\text { pore }\end{array}$ & $\begin{array}{l}\text { Large } \\
\text { pore }\end{array}$ & $\begin{array}{l}\text { Small } \\
\text { pore }\end{array}$ & $\begin{array}{l}\text { Large } \\
\text { pore }\end{array}$ & $\begin{array}{l}\text { Small } \\
\text { pore }\end{array}$ & $\begin{array}{l}\text { Large } \\
\text { pore }\end{array}$ & $\begin{array}{l}\text { Small } \\
\text { pore }\end{array}$ & $\begin{array}{l}\text { Large } \\
\text { pore }\end{array}$ & $\begin{array}{l}\text { Small } \\
\text { pore }\end{array}$ \\
\hline Initial stage & 2.491 & 2.877 & 0.061 & 0.0026 & 0.885 & 1.957 & 0.6213 & 2.3334 & 0.5499 & 4.5664 \\
\hline Water cut of $60 \%$ & 2.452 & 2.853 & 0.044 & 0.0014 & 0.846 & 1.78 & 0.5494 & 2.0718 & 0.4648 & 3.6877 \\
\hline Water cut of $80 \%$ & 2.430 & 2.841 & 0.032 & 0.0006 & 0.826 & 1.707 & 0.5115 & 1.9620 & 0.4225 & 3.3492 \\
\hline Water cut of $90 \%$ & 2.311 & 2.821 & 0.033 & 0.0004 & 0.735 & 1.601 & 0.3331 & 1.8021 & 0.2448 & 2.8852 \\
\hline
\end{tabular}

numbers. With development of computer technologies, 3D digital quantitative characterization of micropore structure become more detailed, which has the apparent superiority.

\section{Reconstruction of digital core}

The real and accurate 3D digital core and its pore network model provide basis for characterization of $3 \mathrm{D}$ pore structure and study on microheterogeneity. At present, construction of digital core is mainly realized through physical experiment and digital reconstruction. Among those technologies, X-ray-CT scanning is the most direct and accurate method. Thus, X-ray-CT scanning is applied to construct digital core. SkyScan1172 New Desktop micro-CT System, produced by SkyScan Company, Belgium, is utilized to conduct CT scanning imaging of core slice without water flooding, and at water cut of 60,80 , and $90 \%$. The resolution of micro-CT scanner system is smaller than $1.0 \mu \mathrm{m}$, and the maximum radial voltage is $100 \mathrm{kV}$. In micro-CT system, the sample platform rotates in a certain step size to obtain projection images of sample of different angles, and Feldkamp cone light beam algorithm is utilized to reconstruct a series of section images. Then, the complete 3D image is reconstructed, and the image includes information and density of interior super-microstructure within the range of object. Reconstruction of 3D digital core has five steps. The first step is to cut $\Phi 2.5 \mathrm{~cm} \times 1.0 \mathrm{~cm}$ core samples without water flooding and at water cut stages of 60, 80, and 90\% in Well LN26 and GJ315-7. The second step is to define the rotation step size of sample as $0.25^{\circ}$, and "take picture" of core sample every step size during $360^{\circ}$ rotation of core slice in CT machine. The core slice is photographed 1440 times, and 1440 pieces of reconstructed 2D images are obtained. The third step is to define the scanning area of core sample with Rhinoceros software and determine the range of threshold of gray processing of image. The fourth step is to conduct binarization processing of $2 \mathrm{D}$ image, and the treated images only have black and white colors. Thus, the gray range is divided into the target and the background. The throat and rock skeleton are differentiated to obtain 2D image of core skeleton and pore, which is convenient for measurement and observation. The pictures are shown in Fig. 5a-d. The fifth step is to reconstruct $3 \mathrm{D}$ digital core to obtain pore and skeleton structure. 3D reconstruction of screenshot at all radial step size is conducted through reconstruction of simulating geological formation process of sandstone to obtain 3D model of digital core (Hou et al. 2007), which is shown in Fig. 6a. Then, the model is simplified to reflect pore structure and obtain pore structure of $3 \mathrm{D}$ network model, which is shown in Fig. 6b. The skeleton structure is shown in Fig. 6c. Finally, the corresponding porosity, throat size and particle diameters, etc. are calculated.

\section{D model of pore network}

With the statistical properties almost as same as those of real core, 3D digital core reconstructed through CT scanning has the complex pore structure. Its pore shape and size are randomly distributed, and the throat connecting pore is complex. The characteristics of pore result in great difficulty in quantitatively characterizing pore structure. Thus, based on digital core constructed through CT scanning, the pore parameters of reconstructed digital core are optimized through process simulation method (Mustafa et al. 2009), and the pore network model is extracted accurately from 3D digital core with maximal ball algorithm presented by Al-Kharusi and Blunt (2007). After effectively identifying and defining pore and throat of rock, the pore diameter, throat diameter, pore volume, throat volume, coordination number, pore-throat ratio, shape factor and throat length, and other key parameters are measured. Then, quantitative characterization of micropore structure is conducted through mathematical statistics. The structure of 3D pore network model corresponds well to that of real rock, and the topological structure of real pore space reflects the characteristics of initial pore structure. 
Fig. 5 a Rock skeleton and 2D pore figure of initial core of Well LN2-6. b Regional rock skeleton and 2D pore figure of Well LN2-6 at water cut of $60 \%$. c Rock skeleton and $2 \mathrm{D}$ pore figure of Well LN2-6 at water cut of $80 \%$. d Rock skeleton and 2D pore figure of Well LN2-6 at water cut of $90 \%$
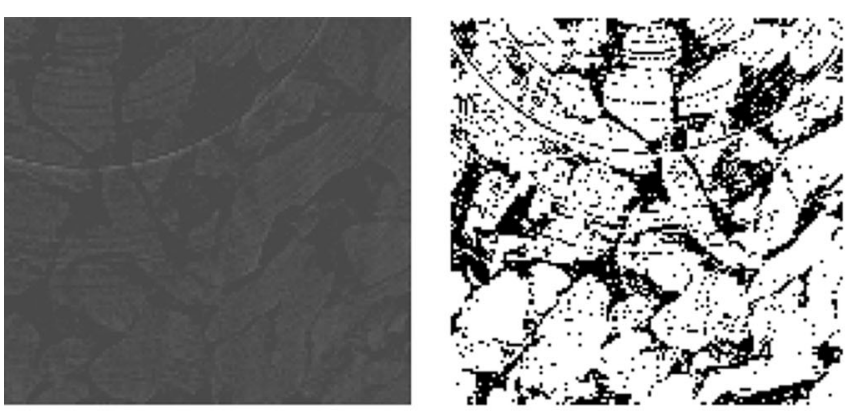

a
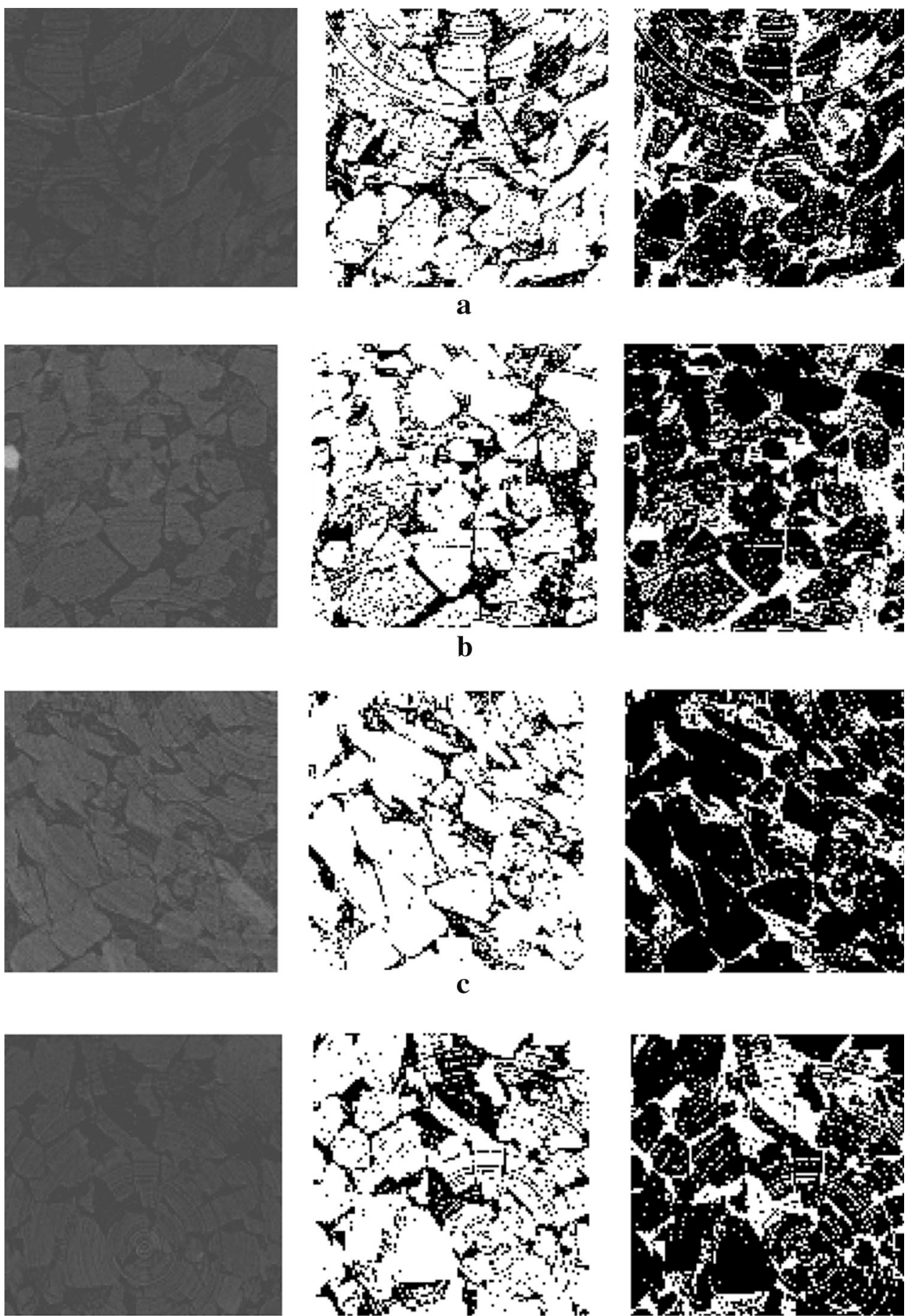

c

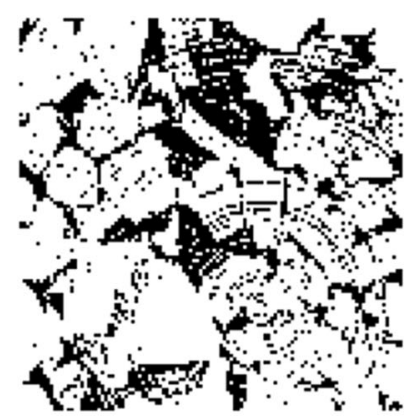

d

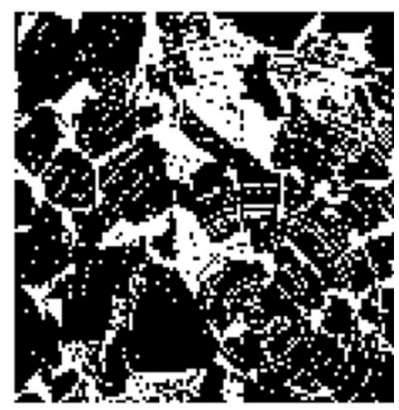

Analysis of pore network model of pore structure at different water cut

Based on 3D pore network model, the micropore parameters of cores in Well LN2-6 and GJ315-7 without water flooding are simulated, and the pore size and the throat size are analyzed. The statistics of throat parameters of pore network model is given in Table 5. The table shows that the high- porosity and high-permeability reservoir in the Jidong Oilfield has a strong heterogeneity, which creates the large difference and disperse distribution of throat radius.

The probability distribution data of pore and throat radius of digital core of Well LN2-6 and GJ315-7 at water cut of 60,80 , and $90 \%$ are analyzed to obtain data at three stages, which are shown in Figs. 7 and 8. The results show that after long-term flooding, the probability distribution of 
Fig. 6 Digital core.

a Reconstructed 3D model,

b pore structure of digital core,

c skeleton of 3D model

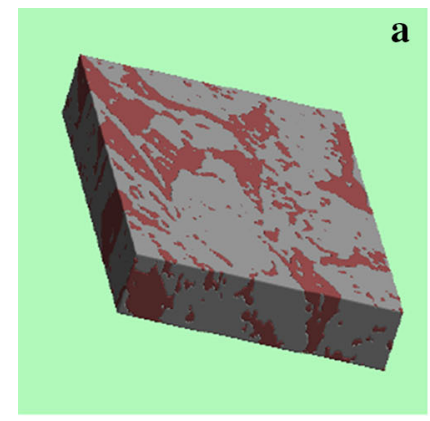

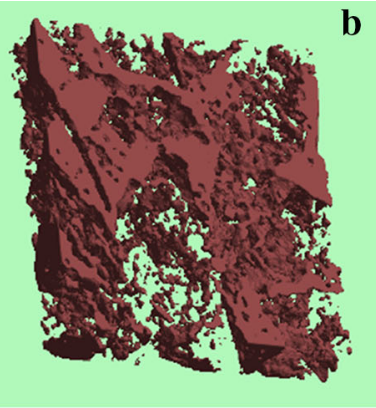

b

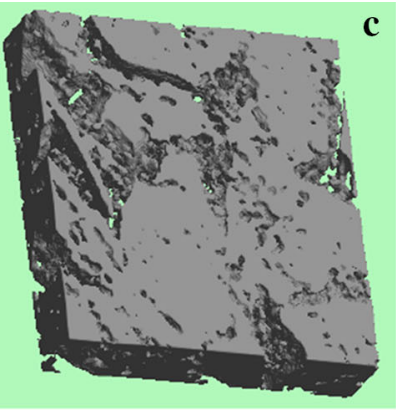

throat radius of core increases as water cut increases, which is consistent with the feature of digital core and variation of fractal dimension of pore structure. It is proved that simulation of core in Well LN2-6 and GJ315-7 with network model conforms to topology of real core. Moreover, after long-term flooding in reservoir of the Jidong Oilfield, the separation of pore and throat becomes better, and microheterogeneity of reservoir gradually becomes weaker. The rule has not been reported before (Elliott and Dover 1982; Sorbie et al. 1989; Lymberopoulos and Payatakes 1992; Xu et al. 1999; Fredrich et al. 1995; Fredrich 1999; Delerue et al. 1999; Lindquist and Venkatarangan 1999; Liang et al. 2000; Blunt (2001); Radlinski et al. 2002; Siddiqui and Khamees 2004; Coenen et al. 2004; Arns et al. 2004, 2005; Knackstedt et al. 2006; Al-Kharusi and Blunt 2007; Tomutsa et al. 2007; Hou et al. 2007; Youssef et al. 2008; Dong and Blunt 2009; Mustafa et al. 2009; Xu et al. 2010; Peng et al. 2012; Saurabh et al. 2013; Theis et al. 2014).

\section{Fractal characterization of seepage law}

\section{Fractal model of relative permeability}

Based on capillary pressure data, the water relative permeability is calculated with Purcell relative permeability

Table 5 Statistics of parameters of pore network model

\begin{tabular}{lll}
\hline Model & LN2-6 & GJ315-7 \\
\hline Size of model/mm & & \\
$\mathrm{X}$ & 3 & 2.138 \\
$\mathrm{Y}$ & 3 & 2.138 \\
$\mathrm{Z}$ & 2.46 & 2.138 \\
Porosity of model & 0.3213 & 0.3012 \\
Number of pore & 2287 & 2012 \\
Number of throat & 5009 & 3657 \\
Throat diameter/micrometer & & \\
Minimum & 2.4 & 2.47 \\
Maximum & 25.9 & 25.7 \\
Average & 14.8 & 15.1 \\
\hline
\end{tabular}

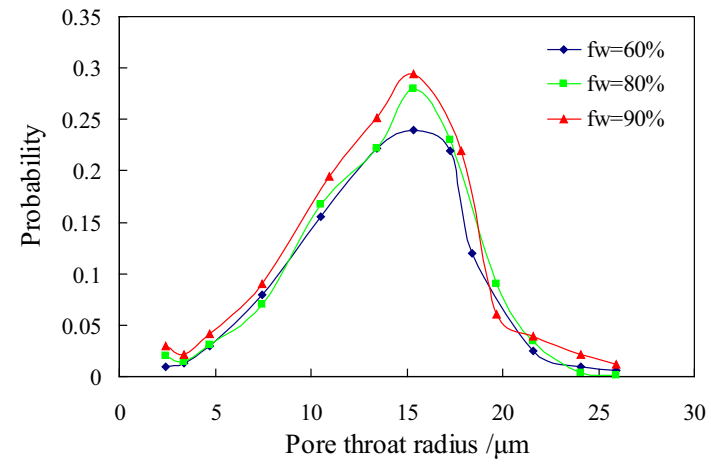

Fig. 7 Relation between probability distribution of pore throat radius of core and water cut in Well LN2-6

model. The fractal of water relative permeability is expressed by Purcell (1949):

$k_{\mathrm{rw}}=\left(S_{w}\right)^{\frac{5-D}{3-D}}$

Based on capillary pressure data, the fractal of oil relative permeability is calculated with Brooks-Corey relative permeability model, and it is expressed by Brooks and Corey (1966):

$k_{\mathrm{ro}}=\left(1-S_{w}^{*}\right)^{2}\left[1-\left(S_{w}^{*}\right)^{\frac{5-\mathrm{D}}{3-\mathrm{D}}}\right]$

$S_{w}^{*}=\frac{S_{w}-S_{w i}}{1-S_{w i}}$

where $k_{r o}$ is the water relative permeability, decimal; $k_{r o}$ is the oil relative permeability, decimal; $S_{w}^{*}$ is the standardized water saturation, decimal; $S_{w i}$ is the irreducible water saturation, decimal.

\section{Relative permeability curves of different fractal dimensions}

Based on the fractal dimensions of pore structure, the relative permeability curves at different water cut in Well LN103 and GJ315-7 are calculated with Formula (6), (7), and the results are shown in Figs. 9 and 10. The fractal dimension of core of Well GJ315-7 is an average value of 


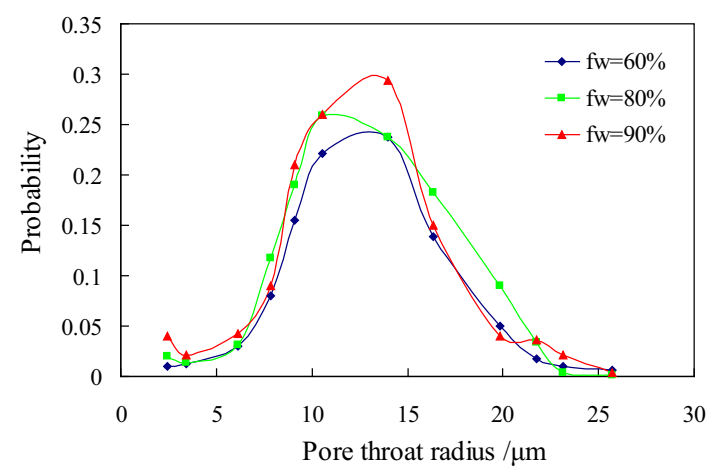

Fig. 8 Relation between probability distribution of pore throat radius of core and water cut in Well GJ315-7

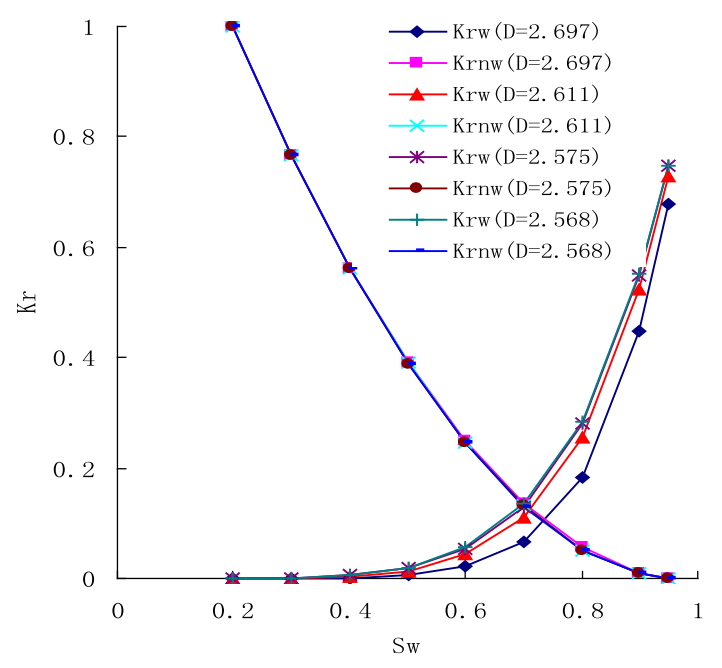

Fig. 9 Relative permeability curves at different water cut of core in Well LN103

large and small pore. The result shows that the fractal dimension of microheterogeneity of core decreases as water cut increases. For the relative permeability curve, the oil relative permeability curves almost coincide, and the water relative permeability curves have a larger difference. With same water saturation, the smaller fractal dimension corresponds to the higher water relative permeability, and vice versa. Comparison of oil and water relative permeability curves at initial state of reservoir shows that the common seepage point of relative permeability of superhigh-water cut reservoir shifts to the left. The common seepage area of oil and water has little change, but water relative permeability increases significantly. Thus, water flow is dominant at super-high water cut. It is showed that for complex faulted oilfield at super-high water cut, only increasing fluid production could not effectively increase oil production because of large increase in water relative permeability. Improvement in development effect needs measures of water block and profile control.

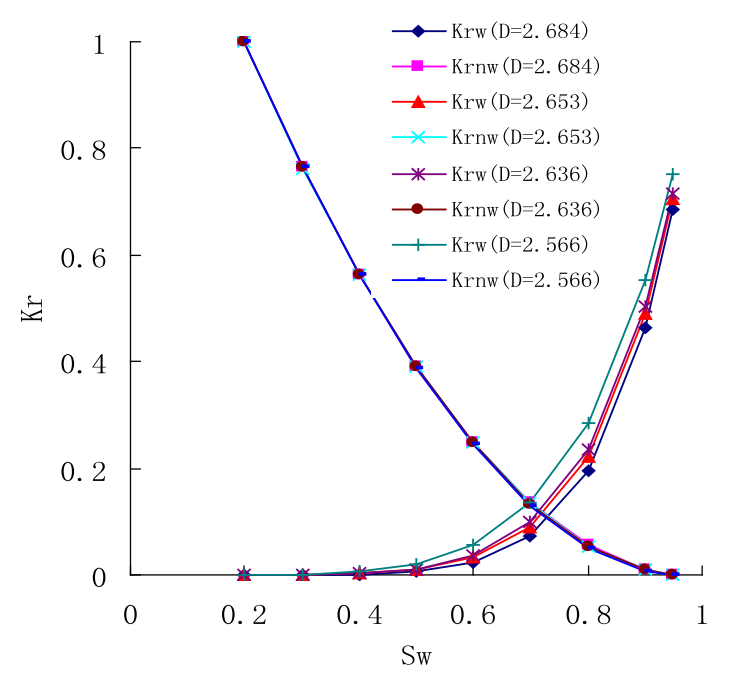

Fig. 10 Relative permeability curve at different water cut of core in Well GJ315-7

\section{Fractal characterization of seepage equation}

Without the effects of capillary pressure and gravity, the seepage equation is expressed by Hewett (1986), $\mathrm{Li}$ (2004):

$f_{w}=\frac{1}{1+\frac{\mu_{\mathrm{w}}}{\mu_{\mathrm{o}}} \frac{k_{\mathrm{r}}}{k_{\mathrm{r}}}}$

Substituting fractal model of $k_{\mathrm{ro}}$ and $k_{\mathrm{rw}}$ into Formula (9), the fractal model of seepage equation without capillary pressure and gravity is expressed by:

$f_{w}=\frac{1}{1+\frac{\mu_{w}}{\mu_{o}} \frac{\left(1-S_{w}^{*}\right)^{2}\left[1-\left(S_{w}^{*}\right)^{\frac{5-D}{3-D}}\right]}{\left(S_{w}\right)^{\frac{5-D}{-D}}} f}$

where $f_{w}$ is the water cut, decimal; $\mu_{o}, \mu_{w}$ are the oil and water viscosity, respectively, $\mathrm{mPa}$ s.

It is showed in fractal model of water cut (10) that without effects of capillary pressure and gravity, the water cut is related to water saturation, fractal dimension D and ratio of water to oil viscosity. When the ratio of water to oil viscosity is constant, the water cut is mainly influenced by $S_{w}$ and fractal dimension D. When water and oil viscosity have a large difference, the change of relation curve between water cut and water saturation is large. The core in Well LN103, with oil viscosity between 3 and $6 \mathrm{mPa}$ s and $\mu_{w} / \mu_{o} \approx 0.1$, represents the light oil reservoir. The core in Well GJ315-7, with oil viscosity of $90 \mathrm{mPa} \mathrm{s}$ and $\mu_{w} / \mu_{o} \approx 0.0055$, represents the heavy oil reservoir. Based on fractal dimension of pore structure, the relation curve of water cut and water saturation in light and heavy oil reservoirs with different fractal dimension is calculated with Formulas (9) and (10), which is shown in Figs. 11 and 12. The fractal dimension $D$ of core in Well GJ315-7 is 


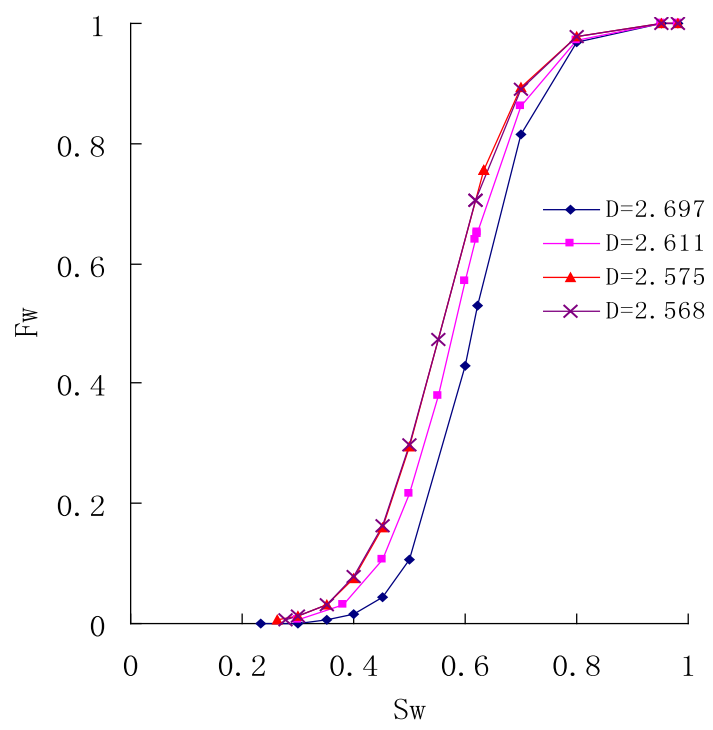

Fig. 11 Relation between saturation and water cut of core in Well LN103

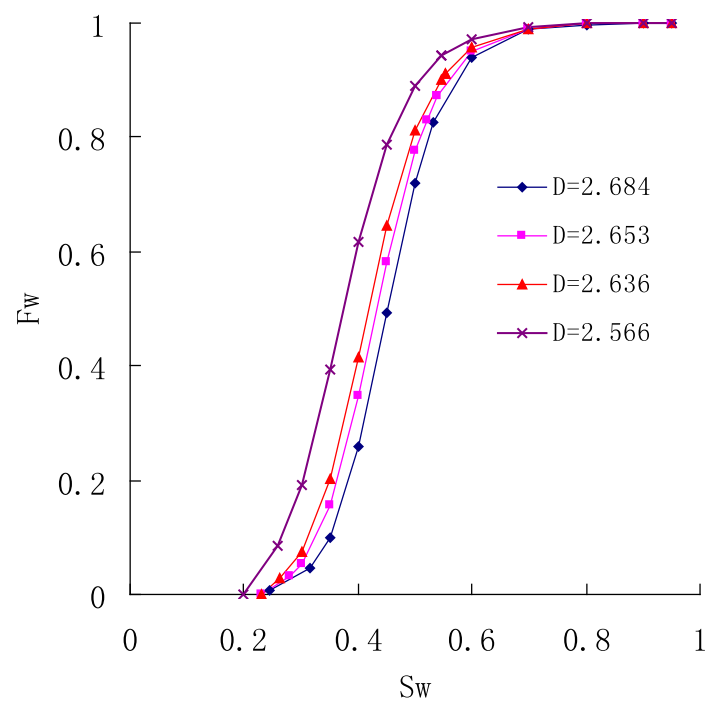

Fig. 12 Relation between saturation and water cut of core in Well GJ315-7

defined as average value of large and small pores. The result shows that the smaller fractal dimension of pore structure corresponds to the higher water cut. It indicates that long-term water flooding would results in weaker microheterogeneity.

\section{Conclusions}

1. Based on mercury-injection data at different water cut during experiment of long-term water flooding, the light and heavy oil reservoir of high porosity and permeability are characterized through fractal theory.
It is showed that after long-term water flooding, the fractal dimension of microheterogeneity, the variable coefficient, the skewness, and the characteristic function, and microheterogeneity of core decreases as the water cut increases. The fractal dimension of large pore is less than that of small one, and the structure of large pore is generally better than that of small one. Fractal dimensions of both large and small pore decrease as the water cut increases.

2. It is showed in $3 \mathrm{D}$ digital core constructed based on X-ray CT scanning and study on microstructure of 3D pore network model that after long-term water flooding, the probability distribution of throat radius of core increases, and the microheterogeneity of core decreases as the water cut increases.

3. Fractal characterization of oil/water seepage law at different water cut shows that the oil relative permeability curves almost coincide, and the water relative permeability curves have a large difference. The higher water cut corresponds to the smaller fractal dimension. The oil/water common seepage point is shifted to the left with larger water relative permeability. Because of large increase in water relative permeability, increasing fluid production alone could not effectively increase oil production. Improvement in development effect needs measures of water block and profile control.

Acknowledgements This work was financially supported by the National Sci-Tech Major Special Project of China (2011ZX05010002 and 2011ZX05052-004), Key Project of Heilongjiang Education Apartment (12511z003).

Open Access This article is distributed under the terms of the Creative Commons Attribution 4.0 International License (http:// creativecommons.org/licenses/by/4.0/), which permits unrestricted use, distribution, and reproduction in any medium, provided you give appropriate credit to the original author(s) and the source, provide a link to the Creative Commons license, and indicate if changes were made.

\section{References}

Al-Kharusi AS, Blunt MJ (2007) Network extraction from sandstone and carbonate pore space images. J Petrol Sci Eng 56:219-231

Angulo RF, Alvarado V, Gonzalez H (1992) Fractal dimensions from mercury intrusion capillary tests. In: SPE 23695, proceedings of the second latin American engineering conference, Caracas, Venezuela, 8-11 March

Arns CH, Knackstedt MA, Pinczewski WV et al (2004) Virtual permeametry on microtomographic images. J Petrol Sci Eng 45:41-46

Arns CH, Bauget F, Limaye A et al (2005) Pore scale characterization of carbonates using X-Ray microtomography. SPE J 10(4):475-484 
Becker MR, Lake LW, Tyler N (1997) Fractal properties of braided fluvial deposits for characterization and simulation of reservoir heterogeneity. In: SPE 38951, proceedings of the fifth latin American and caribbean petroleum engineering conference and exhibition, Rio de Janeiro, Brazil, 30 August-3 September

Bijan B (2003) Quantitative characterization of carbonate pore systems by mercury-injection method and image analysis in a homogeneous reservoir. In: SPE 81479, proceedings of the SPE 13th middle east oil show \& conference, Bahrain, 5-8 April

Blunt MJ (2001) Flow in porous media pore-network models and multiphase flow. Curr Opin Colloid Interface Sci 6(3):197-207

Brooks RH, Corey AT (1966) Properties of porous media affecting fluid flow. J Irrig Drain Div ASCE 92(2):61-88

Cai Y, Yang L, Zhao YH, Wang ZZ (2004) Variation law of the micro-geological features of the reservoir before and after a long term water flooding in $\mathrm{He} 3$ reservoir of Shuanghe oilfield. Petrol Geol OilField Dev Daqing 23(1):24-26

Coenen J, Tchouparova E, Jing X (2004) Measurement parameters and resolution aspects of micro X-ray tomography for advanced core analysis. In: Proceedings of the international symposium of the society of core analysts, Abu Dhabi, UAE, 5-9 October

Delerue J, Perrie E, Yu Z, Velde B (1999) New algorithms in 3D image analysis and their application to the measurement of a spatialized pore size distribution in soils. Phys Chem Earth Part A Solid Earth Geod 24(7):639-644

Dong H, Blunt MJ (2009) Pore-network extraction from microcomputerized tomography images. Phys Rev E 80(3):306-307

Elliott JC, Dover SD (1982) X-ray micro-tomography. J Microsc 126:211-213

Fatt I (1956a) The network model of porous media I. Capillary pressure characteristics. Trans AIME 207:144-159

Fatt I (1956b) The network model of porous media II. Dynamic properties of a single size tube network. Trans AIME 207:160-163

Fatt I (1956c) The network model of porous media III. Dynamic properties of networks with tube radius distribution. Trans AIME 207:164-181

Fredrich JT (1999) 3D imaging of porous media using laser scanning confocal microscopy with application to microscale transport processes. Phys Chem Earth Part A 24(7):551-561

Fredrich JT, Menendez B, Wong TF (1995) Imaging of pore structure of geomaterials. Science 268(5208):276-279

Han H, Loannidis M, Dusseault MB, Xu B (2006) Multiscale porestructure characterization by combing image analysis and mercury porosimetry. In: SPE 100353 , proceedings of the SPE Europec/EAGE annual conference and exhibition, Vienna Austria, 12-15 June

He CZ, Hua MQ (1998) Fractal geometry characterization of reservoir pore structure. Oil Gas Geol 19(1):15-23

Hewett TA (1986) Fractal distributions of reservoir heterogeneity and their influence on fluid transport. In: SPE 15386, proceedings of the SPE annual technical conference and exhibition, New Orleans, 5-8 October

Hou J, Zhang SK, Sun RY, Li AQ (2007) Reconstruction of 3D network model through ct scanning. In: SPE 1006603, proceedings of the SPE Europec/EAGE annual conference and exhibition, London, 11-14 June

Katz AJ, Thompson AH (1985) Fractal sandstone pores: implications for conductivity and pore formation. Phys Rev Lett 54(12): 1325-1328

Knackstedt M, Arns C, Ghous A, Sakellariou A, Senden T, Sheppard A et al (2006) 3D imaging and flow characterization of the pore space of carbonate core samples (SCA2006-23). In: Proceedings of the international symposium of the society of core analysts. Society of Core Analysts, Dublin, CA
Li KW (2004) Characterization of rock heterogeneity using fractal geometry. In: SPE 86975, proceedings of the international thermal operations and heavy oil symposium and western regional meeting bakersfield, California, USA, 16-18 March

Li K, Horne RN (2006) Fractal modeling of capillary pressure curves for the geysers rocks. Geothermics 35:198-207

Li J, Cai Y, Cui YH (2002) Variation features of reservoir pore structure after water flush over a long period of time. Petrol Geol Recover Effic 9(2):68-70

Li XG, Sun CH, Zhao YF (2007) Research on variation rule of reservoir microscopic structures and features in Lamadian Oilfield. Petrol Geol Oilfield Dev Daqing 26(1):79-82

Liang Z, Ioannidis MA, Chatzis I (2000) Geometric and topological analysis of three-dimensional porous media: pore space partitioning based on morphological skeletonization. J Colloid Interface Sci 221:13-24

Libny L, Roberto B, Alfonso Q, Porras CJ, Hugo L (2001) Bimodal behavior of mercury-injection capillary pressure curve and its relationship to pore geometry, rock-quality and production performance in a laminated and heterogeneous reservoir. In: SPE 69457, proceedings of the SPE latin American and caribbean petroleum engineering conference, Buenos Aires, Argentina, 25-28 March

Lin GR, Chen FX, Shao CG et al (2001) Effect of long-term water injection on the pore structure of oil reservoir in maling oil field. J Xi' an Petrol Inst (Nat Sci Ed) 16(6):33-35

Lin YB, Zhang J, Liu XG, Zhou HT (2008) Pore structure features of reservoirs at late high water-cut stage, Lamadian Oilfield, Daqing. Petrol Explor Dev 35(2):215-219

Lindquist WB, Venkatarangan A (1999) Investigating 3D geometry of porous media from high resolution images. Phys Chem Earth (A) 25(7):593-599

Lymberopoulos DP, Payatakes AC (1992) Derivation of topological, geometrical, and correlational properties of porous media from pore-chart analysis of serial section data. J Colloid Interface Sci 150(1):61-80

Ma XF, Zhang SC, Lang ZT (2005) Fractal characterization of characteristic parameters of pore structure. Petrol Geol Recover Effic 12(6):34-36

Mandelbrot BB (1982) The fractal geometry of nature. WH Freeman \& Co., New York, pp 23-24

Mustafa T, Sander S, James F, Yildiray C, Mark K (2009) Pore network modeling of Saudi aramco rocks: a comparative study. In: SPE 126043, proceedings of the 2009 Saudi Arabia section technical symposium and exhibition, AlKhobar, Saudi Arabia, 9-11 May

Peng S, Hu Q, Dultz S, Zhang M (2012) Using X-ray computed tomography in pore structure characterization for a Berea sandstone: Resolution effect. J Hydrol 472:254-261

Perez G, Chopra AK (1997) Evaluation of fractal models to characterize reservoir heterogeneity and performance. SPE Form Eval 12(1):65-72

Perez BL, Miguel AB (2001) Fractal geometry and mercury porosimetry comparison and application of proposed models on building stones. Appl Surf Sci 185(1):99-107

Purcell WR (1949) Capillary pressures-their measurement using mercury and the calculation of permeability. Pet Trans AIME 186:39-48

Radlinski AP, Radlinska EZ, Agamalian M, Wignall GD, Lindner P, Randl OG (1999) Fractal geometry of rocks. Phys Rev Lett 82:3078-3081

Radlinski AP, Ioannidis MA, Hinde AL, Hainbuchner M, Baron M, Rauch H, Kline SR (2002) Multiscal characterization of reservoir rock microstructure: combing small-angle neutron scattering and image analysis. Paper SCA 2002-35, proceedings 
of the 2002 annual symposium of the society of core analysts, Monterey, California, 23-27 September

Ross CM, Kovscek AR (2002) Pore microstructure and fluid distribution in a diatomaceous reservoir. In: SPE 75190, proceedings of the SPE/DOE thirteen symposium on improved oil recovery, Tulsa, Oklahoma, 13-17 April

Shen PP, Li Kevin, Jia FS (1995) Quantitative characterization for the heterogeneity of pore structure by using mercury capillary presure curves. In: SPE 29996, proceedings of the SPE international meeting on petroleum engineering, Beijing, P. R. China, 14-17 November

Shen PP, Liu MX, Jia FS (1998) Application of fractal techniques in reservoir development. In: SPE 50878, proceedings of the SPE international conference and exhibition, Beijing, P. R. China, 2-6 November

Shi CL, Zhang FH, Chen P (2013) Affection of simulating waterflooding by water injection tests on reservoir properties. J Southwest Petrol Univ (Sci Technol Ed) 35(5):87-93

Siddiqui S, Khamees AA (2004) Dual-energy CT-scanning applications in rock characterization. In: SPE 90520, proceedings of the SPE annual technical conference and exhibition, Houston, Texas, 26-29 September

Sigal RF (2013) Mercury capillary pressure measurements on barnett core. SPE Reserv Eval Eng 16:1-11

Sondergeld CH, Ambrose RJ, Rai CS, Moncrieff J (2010) Microstructural studies of gas shales. In: SPE 131771, proceedings of the SPE unconventional gas conference, Pittsburgh, Pennsylvania, USA, 23-25 February

Sorbie KS, Clifford PJ, Jones ERW (1989) The rheology of pseudoplastic fluids in porous media using network modeling. J Colloid Interface Sci 130(1):508-534

Theis S, Xiomara M, Sharon F, Maersk O (2014) 3D imaging of the pore network in the shuaiba reservoir, AI shahaeen field. In:
IPTC 17673, proceedings of the international petroleum technology conference, Doha, Qatar, 20-22 January

Tomutsa L, Silin D, Radmilovic V (2007) Analysis of chalk petrophysical properties by means of submicron-scale pore imaging and modeling. SPE Reserv Eval Eng 10:285-293

Wang TQ, Shi ZJ, Zheng HJ (2005) Fractal characterization of microscopic pore structures of reservoirs both before and after injection. J Oil Gas Technol 27(2):242-244

Xu BM, Kamath J, Yortsos YC, Lee SH (1999) Use of pore-network models to simulate laboratory corefloods in a heterogeneous carbonate sample. SPE J 4(3):179-186

Xu H, Wang CJ, Pang XH, Jiang HQ (2010) 3D network modeling of long-term water-flooded sand reservoir pore throat structure variation. J Southwest Petrol Univ (Sci Technol Ed) 32(4):82-86

Saurabh MS, Yang, JH, John PC, Oussama G, Edo SB (2013) Predicting porosity and permeability of carbonate rocks from pore-to core-scale using medical CT, confocal laser scanning microscopy and micro CT. In: SPE 166252 , proceedings of the SPE annual technical conference and exhibition, New Orleans, Louisiana, USA, 30 September-2 October

Yang S, Dong PC, Cai ZZ, Ji XY, Lei G, Wu ZS, Zhang ZH (2014) The study of remaining oil location in multi-pores at micro and nano scale. In: SPE 171154, proceedings of the SPE russian oil and gas exploration and production technical conference and exhibition, Moscow, Russia, 14-16 October

Youssef S, Bauer D, Han M, Bekri S, Rosenberg E, Fleury M, Vizika O (2008) Pore-network models combined to high resolution $\mu$ CT to assess petrophsical properties of homogenous and heterogenous rocks. In: IPTC 12884, proceedings of the international petroleum technology conference, Kuala Lumpur, Malaysia, 3-5 Dec 